\title{
A functional trait approach for understanding woody species assemblage in tropical deciduous forest
}

\begin{abstract}
Patterns of species distribution can be explained by functional traits of the dominant species and a few key environmental parameters which act as filters on the available pool of species. We performed principal component analysis (PCA) to determine which combination of functional traits best summarizes the grouping of woody species of tropical deciduous forest located in Vindhyan highlands, India. In PCA ordination, the first three axes together explained $98.9 \%$ of the between species variation $(89.5 \%, 6.4 \%$ and $3.1 \%$ for axis 1,2 and 3 , respectively). The woody species exhibited assemblage in the ordination space on the basis of their functional traits. We observed higher leaf area index (LAI), leaf relative water content (RWC) and specific leaf area (SLA) for plant species present at moist sites, whereas, leaf dry matter content (LDMC), mass-based photosynthetic rate (A ) and leaf water use efficiency (WUEi) were found greater for the species present at dry sites. We suggest extensive investigation of functional traits and their ecological significance in grouping of plant communities in tropical deciduous forest.
\end{abstract}

Keywords: tropical deciduous forest, soil moisture content, woody species assemblage, functional traits, Vindhyan highlands
Volume 3 Issue $3-2018$

\author{
Chaturvedi RK,' Raghubanshi AS² \\ 'Center for Integrative Conservation, Xishuangbanna Tropical \\ Botanical Garden, Chinese Academy of Sciences, China \\ ${ }^{2}$ Institute of Environment and Sustainable Development, Banaras \\ Hindu University, India
}

\begin{abstract}
Correspondence: Chaturvedi RK, Center for Integrative Conservation, Xishuangbanna Tropical Botanical Garden, Chinese Academy of Sciences, Menglun, Mengla, Yunnan, 666303, China, Tel 8618288059250 ,

Email ravi@xtbg.ac.cn, ravikantchaturvedil0@gmail.com
\end{abstract}

Received: April 28, 2018 | Published: June 6, 2018

\section{Introduction}

Understanding plant species assemblage requires insight into the mechanisms which determine species richness, and also needs proper investigation of the mechanisms that determine composition of the local species. As compared to species richness, species assemblage is more difficult to assess, because it requires more detailed information about the constituent species. Species assemblage involves not only the total number of species and their abundance, but also the characteristic feature of the species. The Local species assemblage arises partly from stochastic phenomenon such as local species extinctions due to demographic drift and rare occurrence of long distance dispersal events, and partly resulting from deterministic processes associating habitat characteristics with species specific niches. The common approach for the prediction of spatial and temporal patterns of species distribution could be defined by certain "community assembly rules" in terms of a set of "filters" which are responsible for the removal of some species from the total pool of species according to their functional traits. ${ }^{1,2}$ According to the "niche assembly view" of the plant community, the species assemblage in a community is determined by the physiological processes and biological interactions. ${ }^{3}$ Therefore, patterns of species assemblage can be mainly explained by a few key environmental parameters which act as filters on the available pool of species.

We performed principal component analysis (PCA) to determine which combination of functional traits best summarizes the grouping of woody species of tropical deciduous forest (TDF) located in Vindhyan highlands, India $\left(24^{\circ} 18^{\prime} 07^{\prime \prime} \mathrm{N}\right.$ and $83^{\circ} 05^{\prime} 57^{\prime \prime} \mathrm{E}$ to $25^{\circ} 00^{\prime} 17^{\prime \prime} \mathrm{N}$ and $82^{\circ} 37^{\prime} 38^{\prime \prime} \mathrm{E}$ ). The study was conducted at five sites, exhibiting variable soil moisture content (SMC), and representing mature, naturally established and unmanaged TDF of India. ${ }^{4-6}$ The functional traits analysed for the study were: bark thickness (BT), wood specific gravity (WSG), leaf area index (LAI), leaf relative water content (RWC), leaf dry matter content (LDMC), specific leaf area (SLA), leaf carbon concentration (LCC), leaf nitrogen concentration (LNC), leaf phosphorus concentration (LPC), chlorophyll concentration (Chl), mass based stomatal conductance $\left(\mathrm{Gs}_{\max }\right)$, mass based photosynthetic rate $\left(\mathrm{A}_{\max }\right)$, leaf water use efficiency (WUEi), biomass increment (Bio Incr), and relative growth rate (RGR). We also measured SMC as the environmental variable. PCA was done with the help of PC-ORD 5. ${ }^{7}$ For detail information about the study sites, study design and sampling protocol, see Chaturvedi ${ }^{8}$, and Chaturvedi \& Raghubanshi ${ }^{9}$. In PCA ordination, the first three axes together explained $98.9 \%$ of the between species variation $(89.5 \%, 6.4 \%$ and $3.1 \%$ for axis 1,2 and 3, respectively) (Figure 1). SLA was most strongly and negatively associated with axis $1(R=-0.99)$, WUEi showed negative correlation with axis $2(R=-0.96)$, RWC was positively associated with axis 3 $(R=0.96)$, positive correlation was also observed for LAI with axis 4 $(R=0.94), \mathrm{A}_{\max }$ showed negative association with axis $5(R=-0.91)$ and LDMC was positively associated with axis $6(R=0.96)($ Table 1$)$. The environmental variable, SMC showed strong negative correlation with axis $1(R=-0.66)$.

Table I Loading of traits that better explain between species variation in the PCA ordination of the woody species of Vindhyan highlands, India

\begin{tabular}{lllllll}
\hline $\begin{array}{l}\text { Ordination } \\
\text { axes }\end{array}$ & $\mathbf{I}$ & $\mathbf{2}$ & $\mathbf{3}$ & $\mathbf{4}$ & $\mathbf{5}$ & $\mathbf{6}$ \\
\hline LAI & -0.05 & 0.10 & -0.06 & $0.94^{*}$ & 0.30 & -0.02 \\
RWC & -0.10 & 0.26 & $0.96^{*}$ & 0.01 & 0.07 & 0.06 \\
LDMC & 0.00 & -0.07 & -0.06 & -0.04 & 0.22 & $0.96 *$ \\
SLA & $-0.99 *$ & -0.01 & -0.10 & -0.06 & 0.02 & -0.01 \\
$\mathrm{~A}_{\max }$ & -0.05 & -0.05 & 0.06 & 0.29 & $-0.9 I^{*}$ & 0.24 \\
WUEi & -0.02 & $-0.96 *$ & 0.25 & 0.09 & 0.08 & -0.07 \\
Eigenvalue & 35206 & 2510 & 1227 & 293 & 71 & 31 \\
\hline
\end{tabular}

$* \mathrm{P}<0.00 \mathrm{I}$

Source: Chaturvedi ${ }^{8}$ 


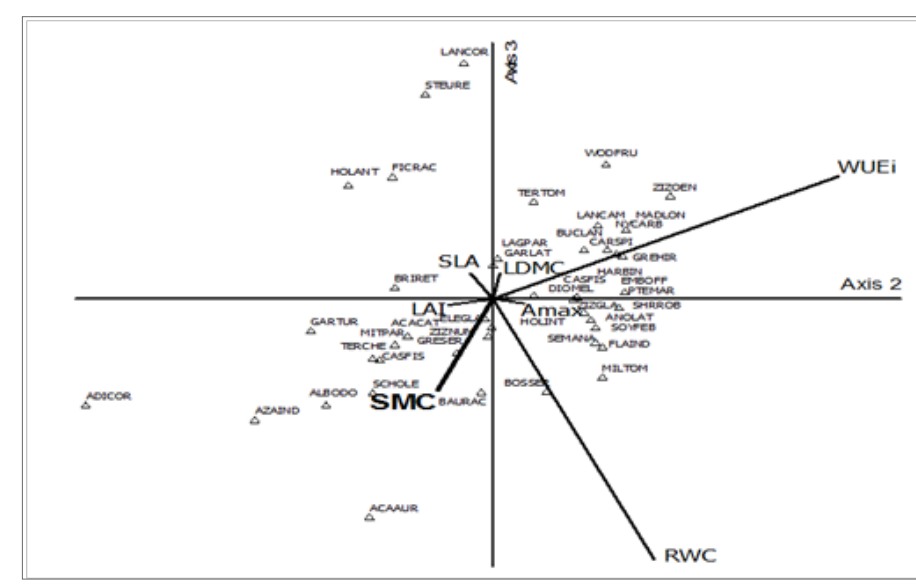

Figure I Ordination plot along the principal components of the woody species of Vindhyan highlands, India based on the following traits: BT, bark thickness;WSG, wood specific gravity; LAI, leaf area index; RWC, leaf relative water content; LDMC, leaf dry matter content; SLA, specific leaf area; LCC, leaf carbon concentration; LNC, leaf nitrogen concentration; LPC, leaf phosphorus concentration; Chl, chlorophyll concentration; $\mathrm{Gs}_{\max }$, mass based stomatal conductance; $A_{\max }$, mass based photosynthetic rate; WUEi, leaf water use efficiency; Bio Incr, biomass increment; RGR, relative growth rate; SMC, soil moisture content. Total variance explained by first axis was $89.5 \%$, by second, $6.4 \%$ and by the third was $3.1 \%$. Species abbreviations are given in appendix. 8

\section{Source: Chaturvedi ${ }^{8}$}

We observed higher LAI, RWC and SLA for plant species present at moist sites, and in the PCA ordination space, some of the important species which were present in this group were: Acacia auriculiformis A.Cunn. ex Benth, A. catechu (L.f.) Willd., Azadirachta indica A. Juss., Bauhinia racemosa Lam., Bridelia retusa (L.) A. Juss, Cassia fistula L., Senna siamea (Lam.) HS Irwin \& Barneby, Elaeodendron glaucum (Rottb.) Pers., Gardenia latifolia Ait., Holarrhena pubescens Wall ex G. Don, Lantana camara L., Lagerstroemia parviflora Roxb., Mitragyna parvifolia (Roxb.) Korth, Pterocarpus marsupium Roxburgh, Schleichera oleosa (Lour.) Merr., Shorea robusta Roth., Terminalia tomentosa (Roxb.) Wight \& Arn., Ziziphus glaberrima (Sedgw.) Santana and Z. nummularia (Burm f.) Wight \& Arn. (Their LAI ranged from 10.0 to 12.1 ; RWC, 98.1 to $98.8 \%$; SLA, 142 to 164 $\left.\mathrm{cm}^{2} \mathrm{~g}^{-1}\right)$.

The remaining three traits (i.e., LDMC, $\mathrm{A}_{\max }$ and WUEi) were found greater for the species present at dry sites, and some important species were: Acacia catechu, Anogeissus latifolia (Roxb. ex DC.) Wall. ex Guillem. \& Perr., Bridelia retusa, Buchanania cochinchinensis (Lour.) Almeida MR. Carissa spinarum L., Diospyros melanoxylon Roxb., Elaeodendron glaucum, Phyllanthus emblica L., Ficus racemosa L., Grewia hirsuta Vahl., Gardenia latifolia Aiton, Hardwickia binata Roxb., Holarrhena antidysenterica Wall, Lantana camara L., Lannea coromandelica (Houtt.) Merr., Lagerstroemia parviflora, Madhuca longifolia ( J König ex L.) Macbr JF., Nyctanthes arbor-tristis L., Pterocarpus marsupium Roxb., Semecarpus anacardium L.f., Shorea robusta Gaertn., Kavalama urens (Roxb.) Raf., Terminalia chebula Retz., T. tomentosa, Woodfordia fruticosa (L,) Kurz, Ziziphus glaberrima, and Z. oenopolia (L.) Mill. (their LDMC ranged from 35.5 to $37.1 \%$; $\mathrm{A}_{\max }, 12.5$ to $14.3 \mu \mathrm{mol} \mathrm{m}^{-2} \mathrm{~s}^{-1}$; WUEi, 54.1 to $58.8 \mu \mathrm{mol}$ $\left.\mathrm{mol}^{-1}\right)$.

Some of the species such as: Acacia catechu, Bridelia retusa, Elaeodendron glaucum, Gardenia latifolia, Holarrhena antidysenterica, Lantana camara, Lagerstroemia parviflora, Pterocarpus marsupium, Shorea robusta, Terminalia tomentosa and Ziziphus glaberrima were present in both the groups. Most of these species have been found at all study sites. ${ }^{10}$

Asynchrony, intra-species variability or plasticity in a species denotes the existence of individuals showing different morphological, physiological and behavioral responses to environmental conditions. ${ }^{11-13}$ The woody species investigated in this study show asynchrony and intra-specific variability at different study sites and in different seasons. ${ }^{12}$ They have high adaptive capacity and plasticity according to variations in soil moisture availability. ${ }^{14,15}$ Therefore, they are generally dominant and present at all the sites.

Dominant plant species have been reported to strongly influence the size as well as turnover rate of the aboveground carbon stocks. ${ }^{16-18}$ The effects of these dominant species are determined particularly by the quantity and quality of resources which they return back to the soil, which is in turn influenced by their functional traits. ${ }^{2,13}$ Within a specified envelope of a given climate and substrate, these functional traits influence the rates of carbon accumulation and carbon loss, as well as the density and longevity of the carbon stocks in equilibrium condition. Therefore, major importance should be given on the protection of the dominant plant species, especially the tree species which are abundant in the forest. These species have high adaptability as well as plasticity according to variations in soil moisture availability. ${ }^{19-21}$ Therefore, they can help in mitigating the ecological impacts of global climate change by enhancing carbon sequestration.

\section{Conclusion}

Our study highlights the importance of functional traits for understanding woody species assemblage in tropical deciduous forest. Moreover, functional traits of the dominant plants over large areas can also influence water and heat biophysical feedbacks from earth surface to the atmosphere, and thus impact climate directly. For example, leaf stomatal conductance and rooting depth of dominant plant species affect ecosystem evapotranspiration. Canopy architecture, leaf morphology and lifespan affect albedo, sensible heat, roughness, and the balance between infiltration and runoff. All these processes feedback onto the atmosphere and have the potential to influence climate at the local, regional, or larger scales, depending on the size of vegetation patches. Therefore, we suggest extensive investigation of functional traits and their ecological significance in grouping of plant communities in tropical deciduous forest.

\section{Acknowledgements}

R.K.C. thanks Council of Scientific and Industrial Research, India (award no. 09/13(452)/2012-EMR-I) and National Natural Science Foundation of China (NSFC), Chinese Academy of Science, China (award No. 31750110466) for financial support.

\section{Conflict of interest}

The author declares there is no conflict of interest.

\section{References}

1. Lebrija-Trejos E, Pérez-García EA, Meave JA, et al. Functional traits and environmental filtering drive community assembly in a species-rich tropical system. Ecology. 2010;91(2):386-398.

2. Chaturvedi RK, Raghubanshi AS, Singh JS, et al. Plant functional traits 
with particular reference to dry deciduous forests: a review. Journal of Biosciences. 2011;36(5):963-981.

3. Götzenberger L, De Bello F, Brathen KA, et al. Ecological assembly rules in plant communities-approaches, patterns and prospects. Biological reviews. 2012;87:111-127.

4. Singh JS, Chaturvedi RK. Diversity of ecosystem types in India: a review. Proceedings of the Indian National Science Academy-INSA. 2017;83(3):569-594

5. Chaturvedi RK, Raghubanshi AS, Singh JS. Sapling harvest: A predominant factor affecting future composition of tropical dry forests. Forest Ecology and Management. 2017;384:221-235.

6. Chaturvedi RK, Raghubanshi AS, Tomlinson KW, et al. Impacts of human disturbance in tropical dry forests increase with soil moisture stress. Journal of Vegetation Science. 2017;28(5):997-1007.

7. McCune B, Mefford MJ. Multivariate analysis on the PC-ORD system. Version 5 (MjM Software, Gleneden Beach, Ore), India; 2005.

8. Chaturvedi RK. Plant functional traits in dry deciduous forests of India. Ph.D Thesis. Banaras Hindu University, Varanasi, India; 2010.

9. Chaturvedi RK, Raghubanshi AS. Plant Functional Traits in a Tropical Deciduous Forest: An analysis. Lambert Academic Publishing GmbH \& Co. KG, Berlin; 2011.

10. Chaturvedi RK, Raghubanshi AS. Species Composition, Distribution and Diversity of Woody Species in tropical dry forest of India. Journal of Sustainable Forestry. 2014;33(8):729-756.

11. Chaturvedi RK, Raghubanshi AS. Phenotypic plasticity in functional traits of woody species in tropical dry forest. In: Janet B Valentino, Patricia C Harrelson, editors. Phenotypic Plasticity: Molecular Mechanisms, Evolutionary Significance and Impact on Speciation. Nova Science Publishers, Inc. 400 Oser Avenue, Suite 1600, Hauppauge, NY 11788 USA; 2013. p. 35-66.

12. Chaturvedi RK, Raghubanshi AS. Leaf life-span dynamics of woody species in tropical dry forests of India. Tropical Plant Research.
2016;3(1):199-212.

13. Singh JS, Chaturvedi RK. Tropical Dry Deciduous Forest: Research Trends and Emerging Features. Springer Nature Singapore Pte Ltd., Singapore; 2018.

14. Chaturvedi RK, Raghubanshi AS. Soil Water Availability Influences Major Ecosystem Processes in Tropical Dry Forest. MOJ Ecology \& Environmental Sciences. 2018;2(1):1-14.

15. Chaturvedi RK, Raghubanshi AS. Effect of Soil Moisture on Composition and Diversity of Trees in Tropical dry Forest. MOJ Ecology \& Environmental Sciences. 2018;3(1):1-13.

16. Chaturvedi RK, Raghubanshi AS, Singh JS. Carbon density and accumulation in woody species of tropical dry forest in India. Forest Ecology and Management. 2011;262(8):1576-1588.

17. Chaturvedi RK, Raghubanshi AS, Singh JS. Effect of grazing and harvesting on diversity, recruitment and carbon accumulation of juvenile trees in tropical dry forests. Forest Ecology and Management. 2012;284:152-162.

18. Chaturvedi RK, Raghubanshi AS. Assessment of carbon density and accumulation in mono- and multi-specific stands in tropical dry forests of India. Forest Ecology and Management. 2015;339:11-21.

19. Chaturvedi RK, Raghubanshi AS, Singh JS. Leaf attributes and tree growth in a tropical dry forest. Journal of Vegetation Science. 2011;22(5):917931.

20. Chaturvedi RK, Raghubanshi AS, Singh JS. Growth of tree seedlings in a dry tropical forest in relation to soil moisture and leaf traits. Journal of Plant Ecology. 2013;6(2):158-170.

21. Chaturvedi RK, Raghubanshi AS, Singh JS. Relative effects of different leaf attributes on sapling growth in tropical dry forest. Journal of Plant Ecology. 2014;7(6):544-558. 